\title{
A multidisciplinary clinic approach improves survival in ALS: a comparative study of ALS in Ireland and Northern Ireland
}

\author{
James Rooney, ${ }_{1}^{1}$ Susan Byrne, ${ }^{1}$ Mark Heverin, ${ }^{1}$ Katy Tobin, ${ }^{1}$ Alison Dick, ${ }^{2}$ \\ Colette Donaghy, ${ }^{2}$ Orla Hardiman ${ }^{1}$
}

${ }^{1}$ Department of Academic Neurology, Trinity Biomedical Sciences Institute Trinity College, Dublin, Ireland 2Department of Neurology, Royal Victoria Hospital, Belfast, UK

Correspondence to Dr James Rooney, Academic Unit of Neurology, Trinity Biomedical Sciences Institute, Trinity College, Dublin, Ireland; jrooney@rcsi.ie

Received 30 September 2014 Revised 11 November 2014 Accepted 4 December 2014 Published Online First 30 December 2014

\section{SLinked}

- http://dx.doi.org/10.1136/ jnnp-2014-309829

\section{CrossMark}

To cite: Rooney J, Byrne $S$, Heverin M, et al. J Neurol Neurosurg Psychiatry 2015:86:496-501.
ABSTRACT

Background Amyotrophic lateral sclerosis (ALS) is a progressive debilitating neurodegenerative disease, with a life expectancy of 3-5 years from first symptom. There is compelling evidence that those who attend a multidisciplinary clinic experience improved survival. The purpose of the study was to explore the survival of patients with ALS ascertained through population-based Registers in the Republic of Ireland (Rol) and Northern Ireland (NI), and to determine whether centralisation of services confers advantage compared with communitybased care supported by a specialist care worker. Methods The island of Ireland is divided into two countries, Rol and $\mathrm{NI}$, each with an independent healthcare system. Both countries have population-based ALS Registers with full ascertainment. Data from all 719 incident ALS cases from Ireland and $\mathrm{NI}$, diagnosed between 1 January 2005 and 31 December 2010, were used in the analysis.

Results A survival benefit was identified for patients who attended the multidisciplinary ALS clinic in the Rol. (HR $0.59,95 \% \mathrm{Cl} 0.49$ to $0.71, \mathrm{p}<0.001$ ). This difference was preserved following multivariate analysis. A trend towards improved survival was noted for patients with ALS from NI when compared with Rol patients who did not attend a multidisciplinary clinic. Conclusions Centralised multidisciplinary care confers a survival advantage for patients with ALS and is superior to devolved community-based care. We propose that multiple decision-making processes within a multidisciplinary setting lead to an enriched set of clinical encounters for the patient and carer that enhances clinical outcome.

\section{INTRODUCTION}

Amyotrophic lateral sclerosis (ALS) is a progressive debilitating neurodegenerative disease with a life expectancy of 3-5 years from first symptom, and death from respiratory failure. ${ }^{1}$ Riluzole is the only medication that slows disease progression. ${ }^{2}$ Non-invasive ventilation (NIV) confers a survival and quality of life benefit in patients with ALS. ${ }^{3} 4$ It remains unclear whether gastrostomy improves survival, as there have been no randomised controlled trials. ${ }^{5}$

There is compelling evidence that those who attend a multidisciplinary clinic experience improved survival (Ireland, ${ }^{6} 7$ Holland, ${ }^{8}$ Italy, ${ }^{9}$ Sheffield ${ }^{10}$ ). Processes by which survival advantage is conferred remain unclear. While those attending specialist clinics are younger and more likely to have familial ALS, inclusion of these factors in multivariate analysis preserves the beneficial effect of specialist clinics. ${ }^{6} 7$ Moreover, a study in Puglia (Italy), which provides services through a network of clinics, did not demonstrate a survival benefit for patients with ALS attending a centralised clinic, suggesting that decentralisation with good access to care may be of equal benefit to patients. ${ }^{9}$ Whether decentralised care with a trained coordinator with expertise in ALS is equivalent to the provision centralised multidisciplinary clinics has not been assessed.

The island of Ireland is divided into two countries, Republic of Ireland (RoI) and Northern Ireland (NI), each with an independent healthcare system. Differences between the two systems of care for patients with ALS have offered the unique opportunity to carry out a population-based study of survival between the two simultaneously ascertained incident cohorts of patients with ALS of similar ancestral origin in two contiguous geographic regions. A centralised multidisciplinary ALS clinic has been in place in the RoI since 1995, providing care for up to $80 \%$ of the ALS population. In 2004, an ALS Care Network was put in place in NI. An ALS Care Network Coordinator was employed to support patients throughout their disease as well as provide education to nonspecialist allied health professionals to facilitate timely coordinated care.

This study compared demographic and survival information for patients with ALS using data from the two independent ALS Registers over a 6-year period, 2005-2010. The purpose was to explore the outcome of patients in the RoI and NI, and to determine whether centralisation of services confers any extra advantage to community-based care supported by a specialist care worker.

\section{METHODS}

Register: The Irish ALS Register was set up in 1993, and the Northern Irish Register was set up in 2004. The RoI covers $70283 \mathrm{~km}^{2}$, with a population of 4.6 million people, compared with NI, which covers $14148 \mathrm{~km}^{2}$, and has a population of 1.8 million people. The Irish ALS Register records information on all people diagnosed with ALS over the age of 15 years. ALS cases are captured by contacting all neurologists and gerontologists in the RoI, reviewing Hospital Inpatient Enquiry (HIPE) Scheme computerised hospital discharge records, 
referrals from community-based services and general practitioners, through the Irish Motor Neurone Disease Association (a patient-support organisation) and via patient self-referral to the National ALS clinic. The Central Statistics Office provides information on all people who have motor neurone disease (MND) or ALS recorded as primary, secondary or tertiary causes of death on their death certificates.

For inclusion on the Register, extensive confirmatory measures such as clinical examination by a specialist, direct chart review and assessment by a neurophysiologist are required. Clinical progression is tracked by regular telephone contact between the register coordinator, healthcare professionals, patients and carers, and by home visits by members of the ALS Research Group. Extensive methods of ascertainment within NI are similar to the RoI Register, on which the design has been modelled. ${ }^{11} 12$

Demographic data on incident ALS cases from RoI and NI, diagnosed between 1 January 2005 and 31 December 2010, were extracted from each Register and entered onto a PASW database (V.18). All cases had definite, probable or possible ALS using the revised El Escorial research criteria.

Variables recorded included sex, date of birth, date of first symptom onset, site of onset (bulbar/limb), date of diagnosis, attendance at a specialist ALS clinic, use of riluzole, use of NIV, use of gastrostomy and date of death or censor.

Multidisciplinary ALS clinic in the RoI: On each visit the patient and his/her carer are seen by a neurologist with specialist expertise in ALS, a specialist ALS nurse and a neuromuscular multidisciplinary team including a physiotherapist, occupational therapist, speech and swallow therapist, and dietician, and given direct next day access to Respiratory Medicine where indicated. Each visit takes between 2 and 3 h.

Clinical assessment of respiratory function is made at each clinic visit, using same-day pulmonary function assessment and overnight oximetry, and, if needed, NIV is initiated at home by a specialist nurse. The physiotherapy service has expertise in respiratory impairment in addition to neurological disability, and provides on site training in secretion management using techniques including breath stacking and the use of cough assist machines. The speech and swallow therapist addresses the management of swallow to prevent aspiration pneumonia. Particular attention is paid to pharmacological management of secretions either with anticholinergic medications (amitriptyline, glycopyrronium), hyoscine patches or, in refractory cases, with botulinum toxin injection or radiation to the salivary glands. Adequate nutrition is addressed at every clinic and patients are weighed, reviewed by the dietician and encouraged to take dietary supplementation. Patients with marked weight loss (greater than 10\%), increasing dysphagia, early respiratory impairment or evolving bulbar symptoms are discussed by the multidisciplinary team during the clinic. Decisions regarding intervention, including gastrostomy insertion, introduction of NIV, training in secretion management and introduction of cough assist, are made collectively.

Three specialist ALS nurses (one hospital based, and two community based and funded by the Irish Motor Neurone Disease Association) are available to make home visits to patients and their families to answer questions and to provide advice on management of ALS. The clinic works closely with community-based clinical professional services (physiotherapy, speech and language therapy, and occupational therapy) and palliative care services. On-site training is provided to communitybased clinical professionals. A rapid access service is provided for patients with increasing symptoms within the community.
Irish patients not attending the specialised multidisciplinary clinic attend general neurology clinics and do not access integrated specialist multidisciplinary care. Care is provided by community-based clinical professionals with links to services within regional hospitals.

ALS/MND Care Network in NI: In 2004 an ALS Care Network was established, funded initially by the Motor Neurone Disease Association of England, Wales and NI and later by the Belfast Health and Social Care Trust. The ALS Care Network Coordinator, who has a nursing background, was appointed to coordinate the care of patients with ALS in NI from diagnosis to death. The Coordinator makes home visits, attends clinic appointments, and is a source of support and education to patients and their local allied health professionals to ensure optimal timeliness and quality of care. A multidisciplinary ALS clinic, comparable to that in the RoI, was not set up in NI until the end of the study period (2010).

Decision to introduce NIV and gastrostomy: Criteria for introduction of NIV in the RoI are aligned to the European Federation of Neurological Societies (EFNS) guidelines. ${ }^{13}$ In the RoI, NIV is initiated either in hospital or at home by a specialist ALS nurse with training in management of respiratory impairment in ALS. In NI, patients are referred to the local respiratory physician, who initiates NIV according to local clinical practice and in accordance with National Institute of Health and Care Excellence (NICE) guidelines.

Radiological gastrostomy tube insertion is offered to those patients in the RoI and NI experiencing a weight loss of greater than $10 \%$ of baseline or increasing dysphagia, and preservation of respiratory function (sniff nasal inspiratory pressure $>40 \mathrm{~cm}$ $\mathrm{H} 20$ and forced vital capacity $>50 \%$ predicted). Gastrostomy is also offered to those with declining respiratory function following successful initiation of NIV in both jurisdictions. Gastrostomy is discussed with family members of those with severe cognitive and behavioural impairment and decisions are made on a case-by-case basis.

\section{Statistical analysis}

Incidence rates reported for geographical area and age categories were manually corrected using the direct method to reflect the underlying population structure in RoI (http://www.cso.ie) and NI (http://www.nisra.gov.uk/).

Demographic and clinical characteristics of the participants are reported as percentages for categorical variables and mean or median values for continuous variable. Comparisons were made using $\chi^{2}$ or Fisher Exact test or two-sample $\mathrm{t}$ test, as appropriate.

To better model the survival effect associated with type of care postdiagnosis (ie, this effect does not exist between onset and diagnosis), ${ }^{7}$ survival time was defined as time from diagnosis to death, covaried for time from onset to diagnosis. Time from symptom onset to diagnosis was compared between groups to ensure lack of lead-time bias. Patients were followed up from their time of diagnosis until death or censor date (31 December 2010). Patients who were alive at the time of analysis were censored. The date for point prevalence was set at 31 December 2010.

In all survival analysis, univariate assessment of the survival effect of categorical variables was carried out using Kaplan-Meier (KM) survival analysis and equality of outcome was assessed using the log-rank test. Multivariate survival analysis was performed using the Cox Proportional Hazards model. Multivariate survival analysis was adjusted for time from onset to diagnosis, age at diagnosis, site of onset, sex, attendance at 


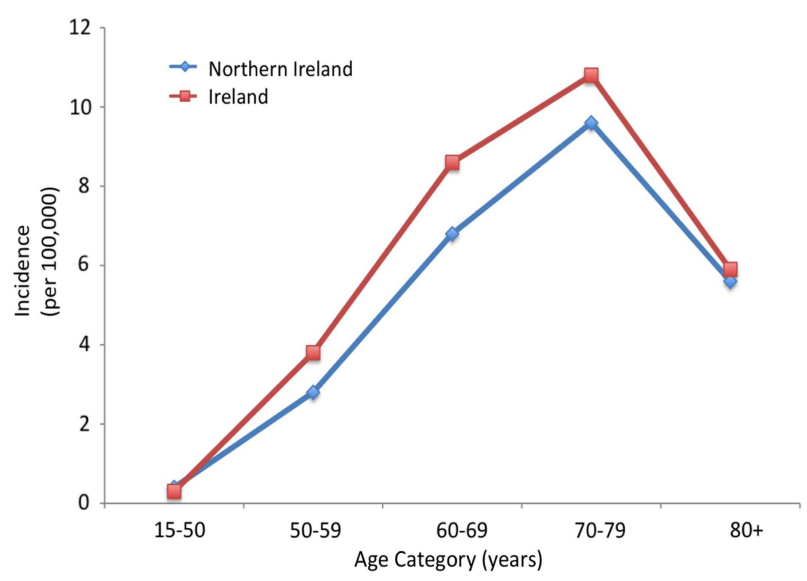

Figure 1 Corrected incidence per age category for Ireland compared with Northern Ireland, 2005-2010.

multidisciplinary ALS clinic, use of riluzole, use of gastrostomy, use of NIV, and use of gastrostomy as well as NIV, and Irish or Northern Irish patient with ALS. Separate multivariate models were built for NI versus RoI comparisons and for general/community care versus multidisciplinary care-this was because collinearity between these variables prevented them from being included in the same model.

Finally, to determine if distance from the specialist centre was a factor in survival for the RoI cohort, the distance from the centroid of each county to the specialist centre was calculated for each patient based on his/her county of residence at the time of diagnosis. The distance was then included in a multivariate Cox model using the following categories: $<50 \mathrm{~km}, 50-100 \mathrm{~km}$, $100-200 \mathrm{~km},>200 \mathrm{~km}$.

All tests were two tailed and statistical significance was set at $\mathrm{p}<0.05$. Statistical analysis was carried out using Stata V.11. ${ }^{14}$ Proportional hazards testing was performed using the estat phtest command in Stata.

\section{RESULTS}

Five hundred and eleven incident patients from RoI and 208 individuals from NI were diagnosed with definite, probable, or possible ALS by El Escorial criteria in the 6-year period from 1 January 2005 to 31 December 2010.
The corrected incidence of ALS for population aged 15 years and above (figure 1 ) was the same in both regions: RoI-2.5 per 100000 (95\% CI 2.0 to 3.0); NI-2.5 per 100000 (95\% CI 1.7 to 3.8$)$. The corrected prevalence for population aged 15 years and above on 31 December 2010 was 6.8 per 100000 (95\% CI 5.9 to 7.6 ) for RoI, and 6.4 per 100000 (95\% CI 5.1 to 7.7) for NI.

Fifty-five per cent $(283 / 511)$ of the RoI patients were male, as compared with 51\% (106) of the NI patients $(p=0.281)$. There was no difference in the age at diagnosis for RoI men compared with NI men, however, RoI women were diagnosed with ALS at a significantly younger age than NI women (see table 1). There was no difference in the site of onset between the two geographic groups, nor was there any difference between the number of months between first symptom onset and a diagnosis of ALS.

\section{Interventions}

Eighty per cent of patients from the RoI (398/496) and 90\% of patients from NI $(187 / 207)$ received riluzole $(p=0.001)$. There was no significant difference in the use of gastrostomy between the two regions: $26.7 \%$ in RoI (136/510) and 35\% in NI (52/ 208) $\mathrm{p}=0.65$. The time from diagnosis to gastrostomy tube insertion was the same for both cohorts (8.6 months in RoI patients compared with 8.5 months in NI patients, $\mathrm{p}=0.93$ ). Pro-rata, twice as many RoI patients were initiated on NIV (30.9\%, 158/511), compared with NI patients $(14.4 \%, 30 / 208$, $\mathrm{p}<0.001)$. There was no difference in the time between diagnosis and initiation of NIV between RoI and NI patients (9.5 months compared with 10.1 months, $\mathrm{p}=0.81$ ). A larger proportion of RoI patients received gastrostomy tube as well as NIV $(14.3 \%, 73 / 511)$ compared with those receiving care in NI $(2.4 \%, 5 / 208, \mathrm{p}<0.001)$.

In the RoI, 340 patients with ALS (66.5\%) attended a multidisciplinary ALS clinic, while the remainder (169) attended local neurology services. The NI cohort also attended local neurology services but within the setting of an established and integrated care network supported by a trained care worker. Of those who attended the specialist multidisciplinary clinic in the RoI, 22.9\% (78/340) received gastrostomies compared with $29.2 \%(110 / 376)$ of those attending general clinics-a finding of borderline significance $(\mathrm{p}=0.055)$.

Patients attending the RoI multidisciplinary clinic were more likely to use NIV (129/340 (38\%)) compared with those

Table 1 Demographic information from patients with ALS in Ireland and NI (age \pm SD)

\begin{tabular}{|c|c|c|c|c|c|c|c|c|}
\hline Variable & $\begin{array}{l}\text { Ireland: general } \\
\text { care }(n=169)\end{array}$ & $\begin{array}{l}\text { Ireland: MDT } \\
(\mathrm{n}=340)\end{array}$ & $\mathrm{p}$ Value & $\begin{array}{l}\text { Ireland: all cases } \\
(n=511)\end{array}$ & NI $(n=208)$ & $\begin{array}{l}\text { p Value: Rol } \\
\text { general vs NI }\end{array}$ & $\begin{array}{l}\text { p Value: Rol } \\
\text { MDT vs NI }\end{array}$ & $\begin{array}{l}p \text { Value: all } \\
\text { Rol vs NI }\end{array}$ \\
\hline \multicolumn{9}{|c|}{ Age at diagnosis } \\
\hline All patients & $68.6 \pm 10.8$ & $62.8 \pm 11.1$ & $<0.0001$ & 64.7 years \pm 11.3 & 65.9 years \pm 11.6 & 0.0213 & 0.0020 & 0.2189 \\
\hline Male & $66.3 \pm 12.0$ & $61.8 \pm 10.7$ & 0.0017 & 63.4 years \pm 11.2 & 62.6 years \pm 11.6 & 0.0268 & 0.5714 & 0.5436 \\
\hline Female & $71.6 \pm 8.1$ & $64.0 \pm 11.5$ & $<0.0001$ & 66.4 years \pm 11.1 & 69.3 years \pm 10.5 & 0.1261 & 0.0002 & 0.0273 \\
\hline \multicolumn{9}{|l|}{ Site of onset } \\
\hline Limb & $50 \%(82)$ & $67 \%(222)$ & & $63 \%(306)$ & $66.5 \%(135)$ & & & \\
\hline Bulbar & $48 \%(78)$ & $32 \%(104)$ & & $37 \%(182)$ & $33.5 \%(68)$ & & & \\
\hline Both & $2 \%(3)$ & $1 \%(2)$ & $<0.001^{*}$ & $1 \%(5)$ & $0 \%(0)$ & $0.001^{*}$ & $0.625^{*}$ & $0.278^{*}$ \\
\hline \multicolumn{9}{|c|}{ Mean time of symptom onset to diagnosis } \\
\hline All & 12.7 months & 13.4 months & 0.6113 & 13.3 months & 14.9 months & 0.1486 & 0.2136 & 0.164 \\
\hline Male & 14.5 months & 13.2 months & 0.0440 & 13.7 months & 14.5 months & 0.9997 & 0.4594 & 0.667 \\
\hline Female & 10.5 months & 13.6 months & 0.5403 & 12.7 months & 15.3 months & 0.0089 & 0.3159 & 0.081 \\
\hline
\end{tabular}


attending general clinics in RoI or availing of integrated community care in NI $(58 / 376(15.4 \%) ; \mathrm{p}<0.001)$.

Additionally, significantly more patients attending a multidisciplinary ALS clinic received a gastrostomy tube as well as NIV (15.9\%, 54/340) compared with patients attending a general (RoI) or regionalised (NI) service $(6.4 \%, 24 / 376, \mathrm{p}<0.001)$.

\section{Survival in Rol compared with NI}

Univariate analysis comparing survival time for all patients within RoI and NI demonstrated a survival advantage in patients from RoI with a median survival from diagnosis to death of 1.22 years compared with 0.98 years in patients from NI $(\mathrm{RR}=1.34, \mathrm{p}=0.0019$; see figure 2$)$. NI patients with bulbar onset (median survival 0.88 years, 95\% CI 0.64 to 1.44) showed a modest improvement in median survival compared with RoI patients with bulbar onset attending the general service (median survival 0.82 years, 95\% CI 0.64 to 1.04 ).

Multivariate analysis, adjusting for country (RoI, NI), time from onset to diagnosis, age at diagnosis, site of onset, sex, use of riluzole, use of gastrostomy, use of NIV (see table 2), demonstrated that RoI patients continued to experience a significant survival advantage (HR $0.72,95 \%$ CI 0.59 to $0.87, \mathrm{p}<0.001$ ), where a hazard rate of less than 1.0 confers a survival benefit.

Survival models of RoI patients only including distance from county centroid showed that the distance from the specialist centre was not a factor in survival (table 3 ).

\section{Survival based on attendance at a specialised ALS multidisciplinary clinic}

RoI patients who attended the multidisciplinary ALS clinic had a younger age of disease onset compared with those who did not attend (62.7 years compared with 68.7 years, p<0.0001). Multivariable analysis adjusting for time from first symptom onset to diagnosis, age at diagnosis, site of onset, sex, use of riluzole, use of gastrostomy and use of NIV, was used to compare survival in RoI patients who attended a multidisciplinary ALS clinic with RoI and NI patients who did not attend a centralised multidisciplinary ALS clinic (table 2). There was a demonstrable survival benefit for patients who attended the multidisciplinary ALS clinic compared with RoI and NI patients who did not attend the clinic (HR 0.59, 95\% CI 0.49 to 0.71 , $\mathrm{p}<0.001)$. Although RoI patients attending the multidisciplinary clinic were more likely to use NIV, this survival benefit could not be accounted for by NIV use alone, gastrostomy, or combined use of NIV and gastrostomy, as previously demonstrated (HR 0.72 , 95\% CI 0.61 to 0.85$)^{7}$

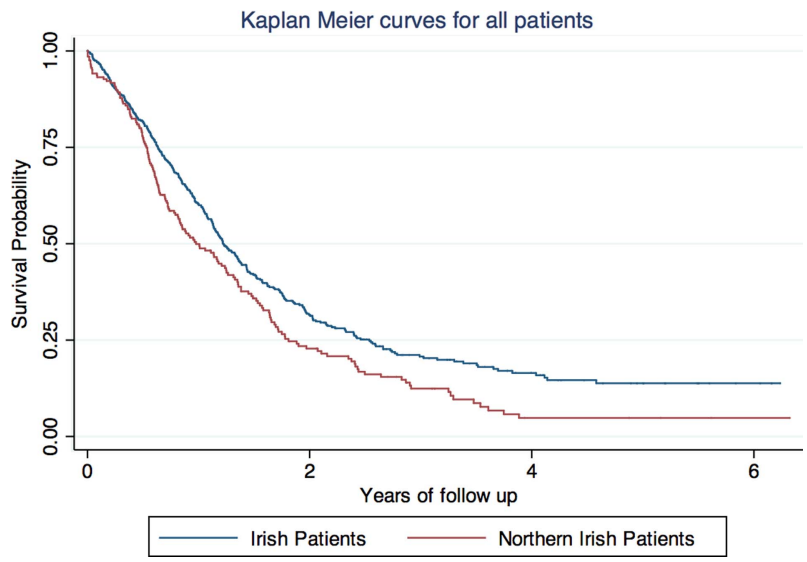

Figure 2 Survival difference between Ireland and Northern Ireland.
Univariate analysis showed no significant difference between RoI patients who attended general neurology ALS clinics and NI patients under the care of the ALS Care Network Coordinator $(\mathrm{RR}=1.2195 \% \mathrm{CI} 0.97$ to $1.51 \mathrm{p}=0.09)$. However, KM survival analyses (figure 3 ) showed a trend towards modest survival advantage of NI patients over general care RoI patients for up to 3 years of follow-up.

\section{DISCUSSION}

The island of Ireland is separated by a political divide, which means that the hospital systems and ALS Registers in the RoI and NI are entirely independent of one another. Despite this, population demographics, rates of capture and epidemiological features of patients with ALS are remarkably similar, reflecting the common ancestral origins of patients in both jurisdictions. This unique separation has permitted the design of populationbased survival study comparing two cohorts, differences between which are primarily a function of the types of health services to which they have access. Our findings suggest that the provision of a centralised multidisciplinary clinic confers a distinct survival advantage over the provision of an integrated community-based care system for patients with ALS.

We used a process of multivariable analysis to covary for factors that are likely to differentiate patients who attend a

Table 2 HRs from Cox multivariate models

\begin{tabular}{|c|c|c|c|c|}
\hline Variable & Strata & HR & $95 \% \mathrm{Cl}$ & p Value \\
\hline \multicolumn{5}{|c|}{ Multivariate regression of $\mathrm{NI}$ vs Rol } \\
\hline Age at diagnosis & Per 10 year increase & 1.4 & 1.32 to 1.58 & $<0.001$ \\
\hline Diagnostic delay & $\begin{array}{l}<31 \text { weeks } \\
31-55 \text { weeks } \\
>55 \text { weeks }\end{array}$ & $\begin{array}{l}1 \\
0.96 \\
0.66\end{array}$ & $\begin{array}{l}0.78 \text { to } 1.20 \\
0.52 \text { to } 0.83\end{array}$ & $\begin{array}{l}0.745 \\
<0.001\end{array}$ \\
\hline Country & $\begin{array}{l}\mathrm{NI} \\
\mathrm{Rol}\end{array}$ & $\begin{array}{l}1 \\
0.72\end{array}$ & 0.59 to 0.87 & 0.001 \\
\hline Sex & $\begin{array}{l}\text { Female } \\
\text { Male }\end{array}$ & $\begin{array}{l}1 \\
1.07\end{array}$ & 0.89 to 1.30 & 0.460 \\
\hline Site of onset & $\begin{array}{l}\text { Limb } \\
\text { Bulbar } \\
\text { Both }\end{array}$ & $\begin{array}{l}1 \\
1.06 \\
1.73\end{array}$ & $\begin{array}{l}0.85 \text { to } 1.31 \\
0.64 \text { to } 4.71\end{array}$ & $\begin{array}{l}0.611 \\
0.283\end{array}$ \\
\hline Riluzole use & $\begin{array}{l}\text { No } \\
\text { Yes }\end{array}$ & $\begin{array}{l}1 \\
0.61\end{array}$ & 0.48 to 0.78 & $<0.001$ \\
\hline Gastrostomy & $\begin{array}{l}\text { No } \\
\text { Yes }\end{array}$ & $\begin{array}{l}1 \\
0.98\end{array}$ & 0.78 to 1.24 & 0.893 \\
\hline NIV & $\begin{array}{l}\text { No } \\
\text { Yes }\end{array}$ & $\begin{array}{l}1 \\
1.23\end{array}$ & 1.00 to 1.51 & 0.048 \\
\hline \multicolumn{5}{|c|}{ Multivariate regression of MDT care vs general care } \\
\hline Age at diagnosis & Per 10 year increase & 1.40 & 1.28 to 1.53 & $<0.001$ \\
\hline Diagnostic delay & $\begin{array}{l}<31 \text { weeks } \\
31-55 \text { weeks } \\
>55 \text { weeks }\end{array}$ & $\begin{array}{l}1 \\
0.96 \\
0.67\end{array}$ & $\begin{array}{l}0.77 \text { to } 1.19 \\
0.53 \text { to } 0.84\end{array}$ & $\begin{array}{l}0.685 \\
0.001\end{array}$ \\
\hline MDT & $\begin{array}{l}\text { No } \\
\text { Yes }\end{array}$ & $\begin{array}{l}1 \\
0.59\end{array}$ & 0.49 to 0.71 & $<0.001$ \\
\hline Sex & $\begin{array}{l}\text { Female } \\
\text { Male }\end{array}$ & $\begin{array}{l}1 \\
1.02\end{array}$ & 0.84 to 1.24 & 0.829 \\
\hline Site of onset & $\begin{array}{l}\text { Limb } \\
\text { Bulbar } \\
\text { Both }\end{array}$ & $\begin{array}{l}1 \\
1.04 \\
1.80\end{array}$ & $\begin{array}{l}0.84 \text { to } 1.29 \\
0.66 \text { to } 4.89\end{array}$ & $\begin{array}{l}0.701 \\
0.249\end{array}$ \\
\hline Riluzole use & $\begin{array}{l}\text { No } \\
\text { Yes }\end{array}$ & $\begin{array}{l}1 \\
0.68\end{array}$ & 0.54 to 0.87 & 0.002 \\
\hline Gastrostomy & $\begin{array}{l}\text { No } \\
\text { Yes }\end{array}$ & $\begin{array}{l}1 \\
0.90\end{array}$ & 0.71 to 1.13 & 0.355 \\
\hline NIV & $\begin{array}{l}\text { No } \\
\text { Yes }\end{array}$ & $\begin{array}{l}1 \\
1.38\end{array}$ & 1.12 to 1.69 & 0.003 \\
\hline
\end{tabular}

Rooney J, et al. J Neurol Neurosurg Psychiatry 2015;86:496-501. doi:10.1136/jnnp-2014-309601 
Table 3 HRs for patient county centroid distance to specialist centre

\begin{tabular}{llll}
\hline $\begin{array}{l}\text { Distance from county centroid } \\
\text { to specialist clinic }(\mathbf{k m})\end{array}$ & $\mathbf{H R}^{*}$ & $\mathbf{9 5 \%} \mathbf{C l}$ & $\mathbf{p}$ Value \\
\hline$<50$ & 1 & - & - \\
$50-100$ & 1.03 & 0.66 to 1.61 & 0.882 \\
$100-200$ & 0.98 & 0.74 to 1.29 & 0.873 \\
$>200$ & 0.99 & 0.74 to 1.32 & 0.940 \\
\hline
\end{tabular}

*After adjustment for age at diagnosis, diagnostic delay, sex, site of onset, riluzole use, gastrostomy, non-invasive ventilation and attendance at the multidisciplinary team (MDT). These results were not significantly altered by stratifying the model by MDT, or by including patients attending the MDT only.

multidisciplinary specialist clinic from those who do not, including time from symptom onset to diagnosis and age at diagnosis. The survival advantage of 8 months experienced by patients attending a multidisciplinary clinic was not explained in full by the use of interventions or medication. We postulate that the survival benefits accrued from the multidisciplinary clinic experience relate in part to the complex decision-making processes that take place both within the clinic and in communication with those in a community setting. We hypothesise that these multiple decision-making processes involve the incorporation of different perspectives on the patient journey, and accordingly lead to an enriched set of clinical encounters for the patient and carer that are then incorporated into the care plan.

Timing of gastrostomy insertion and NIV initiation did not differ between specialist clinic and non-specialised services, however, a larger number of patients from the specialised service used both simultaneously. Thirty-eight per cent of RoI patients attending the specialist clinic had access to NIV compared with $15.4 \%$ in a regionalised service. However, multivariable analysis did not associate the use of NIV and gastrostomy with increased survival. While this contrasts with clinical trials on $\mathrm{NIV}^{3}$ the finding is in keeping with recent analysis of the RoI cohort from 1995 to $2010^{7}$ and may be explained in part by statistical power, and in part by unmeasured confounders including compliance with NIV use and variance in settings.

Although we could not demonstrate that patients in NI experienced an increased survival compared with those in the RoI seen only in the general clinic, the confidence limits on

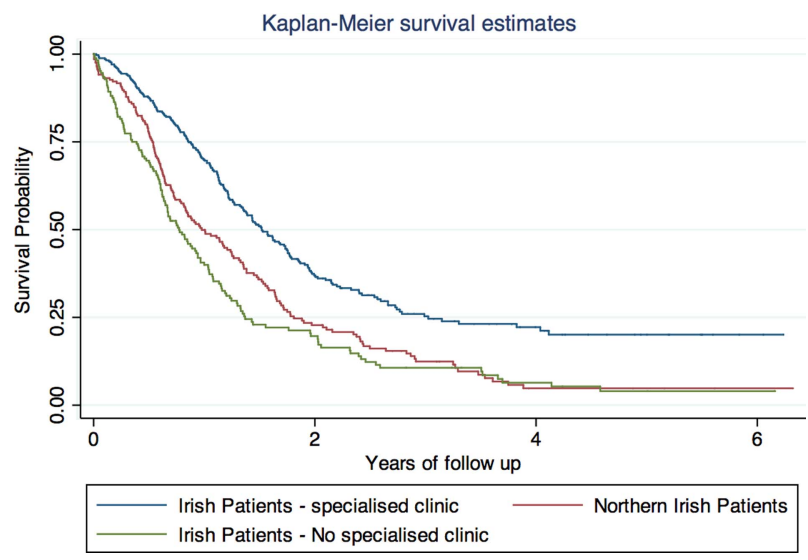

Figure 3 Survival difference between Irish patients in multidisciplinary specialist clinic, compared with Northern Irish patients under the care of the amyotrophic lateral sclerosis Care Network Coordinator, compared with Irish patients at general neurology clinics. these estimates were wide and may be a function of reduced power. This is supported by the trend towards survival advantage of NI patients over general care RoI patients for up to 3 years of follow-up, and suggests that the role of the ALS Network Coordinator in supporting and educating patients and health professionals in ALS management is important.

It was not possible to determine whether the integrated care service in NI provided further advantages with respect to quality of life or carer burden. A previous study in the Netherlands suggested that within the context of multidisciplinary ALS care teams, case managers conferred no extra benefit for patients with ALS or their caregivers. ${ }^{15}$ Although intuitively the case, it remains to be established as to whether the availability of a care worker in the absence of a centralised clinic also provides quantifiable benefits such as improved quality of life and reduced carer burden.

Differences in social deprivation and smoking are unlikely to explain the findings, as mapping of all Ireland social deprivation revealed less extremes of social deprivation in NI in comparison to RoI, ${ }^{16}$ and smoking prevalence among adults are in fact lower in NI $(18.7 \%)^{17}$ compared with RoI $(21.5 \%) .{ }^{18}$ It is possible that cultural and religious differences between NI and RoI may have an influence on survival, however, such an effect's size is likely to be too small to determine with a study of this power. We demonstrated that distance to the specialist centre was not a factor in survival, although this analysis was not performed with a high spatial resolution. Further work at a higher spatial resolution to confirm this and findings by others of a coastal/urban effect on survival ${ }^{19}$ is planned.

This study has limitations. It was not possible to quantify the impact of individual disciplines in the RoI multidisciplinary clinic to determine whether a specific intervention contributed to the survival advantage. It is possible that those not attending the centralised clinic exhibited other negative prognostic indicators that were not taken into account. We have shown previously that executive impairment is predictive of shorter survival, ${ }^{20}$ and it was not possible to include cognitive status as a variable in this analysis as cognitive data were not routinely collected in all patients during the study period. However, as the demographic features of the two populations were similar in all other regards, we believe this to be an unlikely explanation for the differences.

Our data supports our previous findings and those of others, that attendance at a specialist multidisciplinary ALS clinic is beneficial to patients, and should be considered a standard of care in the management of ALS. The precise advantage conferred by the multidisciplinary clinic remains to be established, but is likely related to the complex decision-making processes from differing vantage points that take place among experienced professionals within the clinic. Further work to deconstruct the functionality of the multidisciplinary clinic is required to test this hypothesis. In the absence of a centralised specialist clinic, the availability of a specialist care network coordinator may be advantageous.

Contributors JR analysed the data and wrote the manuscript. SB designed the study, analysed the data and wrote the manuscript. MH maintained the database, assisted with data collection and edited the manuscript. KT and AD assisted with data analysis and edited the manuscript. CD set up the Northern Irish ALS register, assisted with data collection and edited the manuscript. $\mathrm{OH}$ set up the Irish ALS register, designed the study, collected the data, and wrote and edited the manuscript.

Funding The research leading to these results has received funding from the Health Research Board Interdisciplinary Capacity Enhancement Programme, the European Community's Seventh Framework Programme (FP7/2007-2013) under the Health 
Cooperation programme and the project EUROMOTOR (No259867), from the European Joint Programme in Neurodegeneration (SOPHIA and ALS-CarE) and the Charities Research Motor Neurone and the Irish Motor Neurone Disease Association.

Competing interests JR and SB were funded by the Health Research Programme Clinical Fellowship Programme. KT is a HRB Interdisciplinary Capacity Enchancement Fellow. $\mathrm{OH}$ is funded by the Health Research Board Clinician Scientist Programme. She has received honoraria for providing expert advice to Novartis, Merck Serono, Biogen Idec and Cytokinetics.

Ethics approval The Irish ALS Register complies with Irish Data protection legislation (1988 and 2003), and has been approved by Beaumont Hospital Ethics Committee (02/28 and 05/49). Approval for the study is from Beaumont Hospital Ethics Committee (05/49).

Provenance and peer review Not commissioned; externally peer reviewed.

Data sharing statement Data sharing requests are made in writing through Professor Hardiman (hardimao@tcd.ie) and require a formal data sharing agreement with approval from the University Technology Transfer Department. Data sharing agreements must include details on how the data will be stored, who will have access to the data and intended use of the data, and agreements as to the allocation of intellectual property.

\section{REFERENCES}

1 Kiernan MC, Vucic S, Cheah BC, et al. Amyotrophic lateral sclerosis. Lancet 2011;377:942-55.

2 Bensimon G, Lacomblez L, Meininger V. A controlled trial of riluzole in amyotrophic lateral sclerosis. ALS/Riluzole Study Group. N Eng/ J Med 1994;330:585-91.

3 Bourke SC, Tomlinson M, Williams TL, et al. Effects of non-invasive ventilation on survival and quality of life in patients with amyotrophic lateral sclerosis: a randomised controlled trial. Lancet Neurol 2006;5:140-7.

4 Newsom-Davis IC, Lyall RA, Leigh PN, et al. The effect of non-invasive positive pressure ventilation (NIPPV) on cognitive function in amyotrophic lateral sclerosis (ALS): a prospective study. J Neurol Neurosurg Psychiatry 2001;71:482-7.

5 Chiò A, Logroscino G, Hardiman 0, et al. Prognostic factors in ALS: a critical review. Amyotroph Lateral Scler 2009;10:310-23.
6 Traynor BJ, Alexander M, Corr B, et al. Effect of a multidisciplinary amyotrophic lateral sclerosis (ALS) clinic on ALS survival: a population based study, 1996-2000. I Neurol Neurosurg Psychiatry 2003;74:1258-61.

7 Rooney J, Byrne S, Heverin M, et al. Survival analysis of Irish amyotrophic lateral sclerosis patients diagnosed from 1995-2010. van der Brug MP, editor. PLoS One 2013;8:e74733

8 Van den Berg JP, Kalmijn S, Lindeman E, et al. Multidisciplinary ALS care improves quality of life in patients with ALS. Neurology 2005;65:1264-7.

9 Zoccolella S, Beghi E, Palagano G, et al. ALS multidisciplinary clinic and survival. Results from a population-based study in Southern Italy. I Neurol 2007;254:1107-12.

10 Aridegbe $\mathrm{T}$, Kandler $\mathrm{R}$, Walters $\mathrm{SJ}$, et al. The natural history of motor neuron disease: assessing the impact of specialist care. Amyotroph Lateral Scler Frontotemporal Degener 2013;14:13-19.

11 Donaghy C, O'Toole O, Sheehan C, et al. An all-Ireland epidemiological study of MND, 2004-2005. Eur J Neurol 2009;16:148-53.

12 Donaghy C, Clarke J, Patterson C, et al. The epidemiology of motor neuron disease in Northern Ireland using capture-recapture methodology. Amyotroph Lateral Scler 2010;11:374-8.

13 Andersen PM, Borasio GD, Dengler $R$, et al. EFNS task force on management of amyotrophic lateral sclerosis: guidelines for diagnosing and clinical care of patients and relatives. Eur J Neurol 2005;12:921-38.

14 StataCorp. Stata: Release 11. College Station, Texas, USA: StataCorp LP, 2009.

15 Creemers $\mathrm{H}$, Veldink JH, Grupstra H, et al. Cluster RCT of case management on patients' quality of life and caregiver strain in ALS. Neurology 2014;82: 23-31.

16 Haase T, Pratschke J, Gleeson J. All-Island Deprivation Index: towards the development of consistent deprivation for the Island of Ireland. 2012 [cited 2014 Nov 3]. p. 18

17 Cancer Research UK. Tobacco Statistics. 2014 [cited 2014 Nov 3].

18 HSE. Cigarette smoking prevalence in Ireland. 2013 [cited 2014 Nov 3].

19 Keren N, Scott KM, Tsuda M, et al. Evidence of an environmental effect on survival in ALS. Amyotroph Lateral Scler Frontotemporal Degener 2014;15: 528-33.

20 Elamin M, Phukan J, Bede P, et al. Executive dysfunction is a negative prognostic indicator in patients with ALS without dementia. Neurology 2011;76: 1263-9. 